\title{
"Tree Is Life": The Rising of Dualism and the Declining of Mutualism among the Gedeo of Southern Ethiopia
}

\author{
Asebe Regassa Debelo ${ }^{1 \dagger}$, Abiyot Legesse ${ }^{1 \dagger}$, Tema Milstein ${ }^{2 * \dagger}$ and Ongaye Oda Orkaydo ${ }^{1 \dagger}$ \\ ${ }^{1}$ Dilla University, Dilla Town, Ethiopia, ${ }^{2}$ University of New Mexico, Albuquerque, NM, United States
}

This study investigates ecocultural discourses and practices among the Gedeo in southern Ethiopia within the contexts of globalizing commodification of nature, successive governmental extractivist and conservationist discourses, and increasingly influential colonial

OPEN ACCESS

Edited by:

Todd Norton,

Boise State University,

United States

Reviewed by:

Leah Sprain,

University of Colorado

Boulder, United States

Samantha Senda-Cook,

Creighton University,

United States

${ }^{*}$ Correspondence: Tema Milstein

tema@unm.edu

${ }^{+}$All authors equally contributed to this paper and, thus, share equal authorship.

Specialty section: This article was submitted to Science and Environmental Communication,

a section of the journal Frontiers in Communication

Received: 19 April 2017

Accepted: 31 July 2017

Published: 21 August 2017

Citation:

Regassa Debelo A, Legesse A Milstein T and Orkaydo OO (2017)

"Tree Is Life": The Rising of Dualism and the Declining of Mutualism among the Gedeo of Southern

Ethiopia.

Front. Commun. 2:7.

doi: 10.3389/fcomm.2017.00007 present religious systems. Our analysis illustrates ways in which indigenous Gedeo understandings of reciprocal ecological coexistence are rooted in cultural knowledge, values, and customs. However, competing forms of knowledge introduced in the form of governance, commerce, conservation, and religion have resulted in an in-process shift from traditionally, spiritually maintained mutualist human-environment relations to dualist commodified relations, particularly among youth, and dualist expert-reliant conservationist relations emanating from governmental bodies. By examining a traditional meaning system during an explicit process of erasure, the study points to ways local meanings of, and narratives about, ecocultural interactions are produced and communicated within wider contexts of power, and illustrates tensions among traditional, governmental, capitalist, conservationist, and religious environmental ontologies in everyday and institutional practice.

Keywords: ecoculture, discourse, traditional ecological knowledge and relations, conservation, agroforestry, Africa

Within a short drive from Dilla ${ }^{1}$ town in southern Ethiopia to its rural environs, one can vividly observe two contrasting aspects of human-environment relations. On the one hand are the Gedeo youth, engaged in cutting trees for firewood, charcoal, and construction materials, and the truck drivers, loading the resulting lumber to sell in nearby towns. On the other hand, a bit further into the hinterlands from the main road, are the elders who continue their sacred beliefs and practices of agroforestry, which protect trees from being cut down, harbor diverse aspects of the ecosystem, and sustain a long-standing coexistence. Whereas Gedeo elders are worried about the decline of indigenous knowledge and the rise of environmental degradation, the youth and government authorities interpret human-environment relations differently. The elders' worry is rooted in the shift that is poignantly illustrated in an ongoing transformation of the core Gedeo mutualist premise of "tree is life" to the increasingly predominant dualist premise, especially among Gedeo youth, of "tree is money in pocket."

In this study, we focus on environmental conservation in the contexts of agroforestry in Gedeo in southern Ethiopia and, more specifically, on hierarchically ordered forms of knowledge and

${ }^{1}$ Dilla town, located about $360 \mathrm{~km}$ to the south of Ethiopia's capital, Addis Ababa, is an administrative headquarters of the Gedeo zone in southern Ethiopia. 
representation that hinge upon competing material-symbolic discourses of traditional, state conservationist, and capitalist actors. By Gedeo agroforestry, we refer to a traditional system of land use in which humans, trees, and perennial and annual crops coexist and complement each other. In this Global South setting, we scrutinize the economic contexts and interests of actors (e.g., elders, youth, and state agricultural experts), to better understand the forces within which these different forms of environmental knowledge interact and to identify which environmental ontology, if any, is prevailing.

Environmental ontologies often swing between two competing paradigms of dualism and mutualism (Descola and Pàlsson, 1996, Merchant, 2003; Descola, 2013). The dualist orientation delineates humans from nature and as capable of controlling "the environment," whereas the mutualist conceptualizes humans and nature as inextricable and as reciprocally constituted. These ontologies are informed by interrelated interests-economic, political, ideological, cultural (Milstein, 2009; Brulle, 2010)—as well as multidimensional engagements of actors with their ecosystems (Ingold, 2000), and are communicated via discursive strategies to define and claim resources and legitimize certain forms of knowledge and action (Schuetze, 2015).

This paper is built on environmental communication as a theoretical framework premised upon the notion that the production and communication of ecocultural discourses create certain forms of knowledge that shape the meanings and perceptions humans construct about the environment, which in turn inform environmental behaviors and actions based on the power positions of actors and the communication channels at their disposal (Robbins, 2012). Actors express environmental values, norms, interests, and policies (Clarke, 2017, p. 2) and, at the same time, discursive forms of environmental communication produced, contested, and negotiated within different contexts within the public sphere mediate environmental beliefs and perceptions (Cox and Pezzullo, 2015).

Ecological knowledge, meanings, and narratives are produced in physical, cultural, and social contexts and communicated within interpersonal, institutional, intercultural, and internatural (Plec, 2013) channels. Carbaugh (1996) explicates that "through everyday practices of communication, people everywhere cultivate ways of being placed with nature, in it, as it, ways of being within the natural realm" (p. 38). These cultivations further are informed by dynamic and shifting values within cultures. For instance, a recent case study in China exhibits ways contemporary farmers' environmental values adhere more to a harmonious proenvironmental New Ecological Paradigm than a mastery exploitive orientation of a Dominant Social Paradigm (DSP) and hints at ways shifts in governmental framing over time from a highly economic focus to a more environmental focus may generationally parallel elder farmers' stronger adherence to a DSP worldview (Orderud and Vogt, 2016).

Indeed, cultural values and worldviews are attached to specific contexts and places, and exhibited and reproduced through specific discourses. For example, competing ontological discourses in the US frame Yucca Mountain as sacred space by First Nations people and as national sacrifice zone for a nuclear waste depository by the US federal government (Endres, 2012). Similarly, discourses in India frame forests in East and West Khasi Hills as sacred groves by followers of traditional beliefs and as dwelling spaces of demonic spirits by Christians (Ormsby, 2013). Closer to the present study's site, the Lower Omo Valley in southern Ethiopia is understood by conservationists as wilderness, by the state as wasteland, and by indigenous communities as home (Turton, 2011). The central argument in all such cases is that environmental discourses are produced, reproduced, in tension, and transformed on the basis of people's ontological notions of humanity's place in nature, and these discourses in turn shape perceptions and interactions with/in/as nature (Cantrill and Oravec, 1996; Milstein, 2011).

This study first introduces the cultural, ecological, and economic contexts guiding Gedeo agroforestry, and provides a brief overview of methodology. We, then, articulate our analytical argument and conclusions that, despite abiding and deeply culturally embedded traditional ecological discourses among elderly indigenous Gedeo and recently introduced governmental discourses of conservation and environmental management, environmental interactions in the Gedeo Zone are experiencing a marked shift from mutualist to dualist and are increasingly guided by capitalist utilitarianism and commodification. Thus, with this case study, we observe a traditional ecological meaning system during an explicit process of erasure, examining tensions among traditional, conservationist, capitalist, religious, and governmental discourses illustrated in everyday and institutional communication.

\section{ECOCULTURAL CONTEXTS OF THE GEDEO OF SOUTHERN ETHIOPIA}

The Gedeo people in southern Ethiopia are predominantly agrarian and inhabit the eastern escarpment of the Great Ethiopian Rift Valley. The people identify themselves as indigenous to the area they inhabit, but the dominant ruling group - the Amhara-has marginalized them for more than a century. Before forceful incorporation into the Ethiopian empire in the late nineteenth century, the Gedeo administered themselves through a traditional sociocultural and political system of governance called the Baalle ${ }^{2}$ system (McClellan, 1988), which persists, albeit in a much weakened form, today. The imposition of the feudal administration's cultural, linguistic, religious, political, and economic systems resulted in an initial partial decline of Gedeo traditional institutions. After Ethiopia's 1991 political and administrative reconfiguration under ethnic federalism, ${ }^{3}$ Gedeo traditional land was designated the Gedeo Zone, ${ }^{4}$ which granted the people a

\footnotetext{
${ }^{2}$ Like the Gadaa system of the Oromo, Kataa system of Konso, and the Luwa system of the Sidama, the Baalle institution of Gedeo is overarching and governs all parts of life, including the ecological, sociocultural, political, administrative, and spiritual. ${ }^{3}$ Ethnic federalism differed from the unitary state system under the former imperial and military regimes, as it granted ethnic groups the right to self-administration and promotion of their languages, cultural practices, and institutions.

${ }^{4}$ The Gedeo Zone is situated between $5^{\circ} 50^{\prime} 26^{\prime \prime}$ and $6^{\circ} 12^{\prime} 48^{\prime \prime} \mathrm{N}$ latitude and $38^{\circ} 03^{\prime} 02^{\prime \prime}$ to $38^{\circ} 18^{\prime} 59^{\prime \prime}$ E longitude, bordering the Sidama Zone in the north and the Oromia regional state in the east, west, and south. Dilla town serves as the zone's administrative capital. The Zone is further divided into six districts: Dilla Zuria, Wonago, Gedeb, Yirgachefe, Bule, and Kochere.
} 
semi-autonomous self-administration in the Southern Nations, Nationalities and Peoples' Regional State. The 2007 Ethiopian Population and Housing Census results reported an estimated 974,000 native speakers of the Gedeo language (CSA, 2007), Gede'uffa, which belongs to the Highland East Cushitic languages of the Afro-asiatic phylum (Hudson, 1981). The language has its unique expressions, in which environmental norms are embedded and reproduced. Core to our study is the often-repeated expression "Tree is life," (in Gede'uffa, "Haqqichchi lubotten") as well as Gede'uffa designations of specific trees whose cutting is prohibited in Gedeo land or in particular places like graveyards and Songo ${ }^{6}$ places. We also pay attention to Gedeo oral traditions, including storytelling regarding respective blessing or cursing of humans who act appropriately or inappropriately toward trees.

The Gedeo were, and still are, predominantly engaged in coffee (Coffea arabica) and ensete ${ }^{7}$ (Ensete ventricosum) cultivation using their traditional knowledge of environmental management to maintain the ecosystem. The ensete and coffee plants need canopy trees for shade and both plants drop leaves that easily decompose, thus increasing soil fertility and conserving soil moisture for both the crop plants and shade trees. The landscape is mostly mountainous, which would have made farming and subsistence difficult had it not been for Gedeo indigenous knowledge gained through long time interactions with the land. By maintaining fertility of the soil and a balance of biodiversity, Gedeo agroforestry supports a large human population on small plots of land (up to 1,300 persons $/ \mathrm{km}^{2}$ ) and, in the recent past, has enabled self-sufficiency in food-security and via cash crop production (Kippie, 2002).

Today, the irony is-despite the evergreen landscape and longstanding traditional knowledge of maintaining the fertility of the soil through agroforestry still in place-four districts in the Gedeo Zone are no longer self-sufficient in food. Only Bule and Gedeb remain self-sufficient due to being cereal crop-producing districts in addition to coffee and ensete (cereal crops are produced in different seasons and used for home consumption throughout the year compared to coffee, which is harvested annually and used only for selling). At the same time, Gedeo agroforestry, now in the process of inscription into United Nations Educational, Scientific, and Cultural Organization (UNESCO) world heritage sites, is recognized for its multidimensional purposes in maintaining balance between ecosystems and productivity of the land through traditional land management system. The recent development in food insufficiency and increasing environmental degradation calls for a deeper investigation into the changing practices of agroforestry, ecocultural knowledge transmission, and overall human-environment interactions reflected and constituted in local environmental discourses.

${ }^{5}$ For translation from Gede'uffa to English, we used native speakers to translate the native expression into Amharic (the working language of the federal state) and then we translated it into English.

${ }^{6}$ Songo is a traditional ritual place where the Gedeo elderly gather and discuss various societal matters and communicate with "Magano." Currently, there are more than 500 Songo institutions in Gedeo.

${ }^{7}$ The ensete plant, commonly known as "false banana," provides staple food for many communities in southern and southwestern Ethiopia, including the Gedeo.

\section{An Ecoculture in Transformation}

The Gedeo experienced extensive social transformations after they became part of greater Ethiopia in the early twentienth century. Their integration into mainstream socioeconomic, cultural, and political structures in the country was asymmetrical as the hierarchical power structure between the dominant ruling class and the subordinated people of the Ethiopian empire differed from traditional Gedeo governance, which granted all clan members equal rights to resources (McClellan, 1988). The feudal system transferred local authority over land to feudal lords appointed from the ruling class. Following the intensification of resource exploitation during this feudal regime and the subsequent military regime's notions of modernization, commercialization and monetization of environmental resources became the major defining features of ecocultural relations throughout Ethiopia. At the same time, traditionally defining features of Gedeo relations with/in environment, including rituals, sacrifices, and respect toward sacred spaces, were pushed to the margins as the two successive regimes denigrated indigenous values and practices of the people (McClellan, 1988).

The introduction of the feudal regime brought a new form of political economy in which military and administrative officials of the state changed customary land rights into private ownership and the local people were reduced to the status of servitude and tenancy. Before the introduction of feudal system, the Abba Gada (the leader of an indigenous sociocultural and political institution) and his subordinates were required to conduct ritual practices through which they brought peace and prosperity to the people. They also conducted different cultural practices that determined the very existence and survival of the society, such as blessings and prayers for health and fertility of the land, humans, and livestock. In turn, clan members channeled some from their surplus into traditional institutions as reciprocity for the services of the leaders and in anticipation of further blessings. Such mutual relations between the Baalle elders and farmers of Gedeo were in existence until the incorporation of the area into the state. However, the introduction of neftegna-gabar ${ }^{8}$ system brought an end to the channeling of parts of surplus produced to the traditional leaders. Consequently, the sociocultural services provided by the Gedeo elders declined and resulted in loose contact between local people and their traditional leaders.

Moreover, driven by the economic importance of coffee, the previous two successive regimes (the 1930-1974 imperial regime under Hailesilasse and the 1974-1991 military regime called the Dereg) changed the farming system from multiple companion plant subsistence farming to mono-cropping. These regimes coerced farmers to grow coffee alone by clearing indigenous trees as well as other plants such as ensete. This practice went against the traditional land use system (multiple crops that were planted together) that was embedded in the culture of the people. Today, only some of these traditional agricultural and ecological relations continue to be practiced and they are adhered to by a disappearing elderly generation.

${ }^{8}$ The Neftegna-gabar system is analogous to landlord-tenant relations in the context of the feudal system in which the landlords (feudal lords) had absolute right and power over the tenants and their resources. 
Gedeo traditional practice allows the cutting of trees only for livelihood purposes such as fuel and house construction. Trees are cut selectively. Only old trees that will regenerate or those strong enough for construction are cut. Cutting fast growing trees such as birbirra (Millettia ferruginea) is prohibited as they shade coffee plants and replenish the soil with vital nutrients. The Gedeo who continue to adhere to cultural values and practices employ the tradition of baboo to maintain reciprocity in environmental interaction, expressed in their native tongue as nophate'n hedhekke baboo hiyotten kokishiyyo hasissa hakichcho, or literally translated as taking good care of offspring of the tree guarantees the continuity of next generations. The baboo tradition normatively governs and maintains the regenerativity of the ecosystem through propagation of tree shoots and seeds that fall on the ground. Moreover, baboo reinforces weeding before coffee harvest to enable the collection of coffee berries and enhance ecosystem regenerativity (Legesse, 2014). Today, largely only elderly Gedeo adhere to baboo approaches, spending a significant part of their time on their farmland, particularly during weeding and slashing seasons, removing weeds by uprooting or cutting weeds close to their roots and slashing branches of bigger trees that would compete with the coffee plants for sunlight and other resources.

The traditional Gedeo agroforestry system is a function of three interdependent variables. First, strong traditional institutions, such as the Baalle and Songo, set rules regarding environmental interactions that will be discussed in detail below. Second, in order to maintain legitimacy and function properly, the authority of these institutions have been upheld and reinforced through communication of ecocultural beliefs, ethics, and customs of the people. The Baalle and Songo institutions can be considered as public spheres where not only environmental rules are set but also competing perspectives engage and shape people's perceptions and actions. Third, the Gedeo, in the traditional context, internalize relations with, in, and as nature as integral to their cultural identity. In elucidating how the Gedeo and their ecosystem are intertwined, Kippie (2002) provides the example of ensete:

Ensete being their livelihood, the Gedeo have no aspect of life, from cradle to deathbed that is not connected with ensete. The Gedeo receive the newborn on dried ensete leaves (hashupha). The placenta is also received in an ensete leaf sheath (hachcho) within the house. The birth of the new baby is announced by placing an ensete leaf (cichcha) on the door... During marriage, the couples spend their first night in a bedding of ensete leaves. When constructing a house, the Gedeo plant ensete at the place of the future pillar (utupha). A dying person is placed on a bedding of ensete leaves and midribs (p. 177).

Recently, however, several interconnected factors have challenged the functioning of Gedeo traditional institutions and the ways ecological relations and cultural identities are mutually constituted. First and foremost, increased population density has exacerbated the scarcity of rural agricultural land and competition for land and forest resources, and Gedeo youth and adults daily flock to nearby towns, particularly to Dilla town, in search of jobs as day laborers. Those Gedeo who live along the GedeoSidama border cut trees to bring to town to sell as construction materials or firewood and pay for basic foodstuffs such as kocho (ensete product), maize, cabbage, meat, and salt before returning home. In addition, it is now common to see trucks, mostly owned and driven by non-Gedeo town-dwellers, collecting tree products from roadside villages and supplying them to towns. At the same time, Gedeo traditional institutions continue to lose legitimacy and power in the face of encroaching influences of Western religion, neoliberal economics, modernist education, and state approaches of governance, all of which undermine traditional values, beliefs, rituals, and customs regarding ecological interaction. Moreover, socioeconomic transformations brought about by the commodification of trees have resulted in increasing transgressions of traditional ecocultural restrictions. As such, this case serves to illustrate ways different actors produce and advocate for competing environmental perspectives, values, interests, policies, and actions, contesting access to and domination of shared ecocultural material and discursive space (Couldry, 2010; Cox and Pezzullo, 2015; Clarke, 2017).

The baboo tradition has been gradually eroding due to the intrusion of Western profit-driven ontologies and a lack of commitment among youth, and many adults, to retain traditional ways. According to many elder participants in this study, this lack of commitment to baboo practice is exacerbated by people's increasing detachment from their rural environments as they increasingly spend most of their time in nearby towns searching for off-farm jobs. One of our participants, who has lived in the area for more than 75 years, stated that local people's commitment to staying on their farmland is gradually declining due to growing interest in off-farm activities. As a result, the Gedeo people who remain on farms often must hire non-Gedeo workers on a contractual basis. Since such workers lack the indigenous knowledge of Gedeo agroforestry, they slash emerging tree seedlings (baboo) that should have been selectively protected to maintain the ecosystem.

Gedeo agroforestry, subsistence living, and their integrated mutualist ecosystem are in jeopardy. An 80-year-old Gedeo elder explains the inextricability of the social and the ecological as follows:

The Gedeo, as a community, are meaningless without the trees, rivers, sacred spaces, mountains, ensete, coffee, and the Baalle and Songo institutions. These are what define us as Gedeo.

Rules for land use and conduct within and among communities are set at the Baalle council, a major assembly of elderly men which meets once every 8 years and devolves its power to the Songo. The Songo, an assembly of elderly men (locally called the Hayyichcha) who meet every week or two in different districts of the Gedeo Zone, discuss contemporary sociocultural and environmental issues within the community and mediate dispute settlement. According to some sources and our own analysis, although both the Baalle and Songo institutions function today, their areas of engagement, legitimacy, power, and autonomy have significantly diminished over the past 100 years 
(McClellan, 1988) and, particularly, over the past 25 years due to the introduction of competing forms of knowledge, governance, and religion. After coming into power in 1991, Ethiopia's current government embarked on co-opting traditional institutions and leaders, which has over the years led to reduced legitimacy of these institutions in the eyes of local communities and, at the same time, strengthened the current government's own authority.

At the same time, over the past decade, conservation discourses have increasingly emerged from zonal, regional, and federal government institutions. This increase was bolstered in 2012 by the UNESCO placing Gedeo agroforestry on the tentative list for inscription as a world heritage site. To realize the inscription, and its associated protections, the zonal administration holds meetings with various stakeholders, drafts conservation rules, and initiates promotions through different media to broadcast the advantages of the inscription, as well as progress made so far. Relatedly, the federal government has launched a watershed management program that mobilizes local communities and government-employed development agents (DAs) (i.e., conservation experts). In the field, these conservation experts provide trainings to members of local communities on integrated watershed management. In the process, the government introduces and promotes discourses of environmental management that aim to shape community perceptions and practices toward "expert"oriented conservation practices and scientific and modernist approaches to environmental relations. These governmental material and symbolic moves toward modernist conservation discourses and practices resonates with Clarke's (2017) framing of environmental communication as a voice through which different actors strive to get their discourses and practices recognized while at the same time recognizing the structures that would give the legitimacy for their actions.

\section{METHODOLOGY}

Data for this paper were collected from rural Gedeo elders, adults, youth, members of the Baalle and Songo institutions, and government DAs ${ }^{9}$ from all districts in the Gedeo Zone in 2014 and $2015 .{ }^{10}$ For data collection, we used interdisciplinary methodological approaches gleaned from geography, environmental

${ }^{9}$ Development Agents are government employees in the Agriculture and Natural Resource Management Offices whose major task is mobilizing and training rural communities in areas of natural resource management, crop production, and animal rearing.

${ }^{10}$ The study presented in the manuscript involved human subjects and, thus, we followed ethical procedures accordingly. The data collection was conducted by the Ethiopian coauthors according to their institution's established University Research Policy; there is no ethics committee in the university and ethics approval is not required as per the institution's guidelines or Ethiopian national laws and regulations. Upon meeting the ethical standards of their institution's University Research Policy, the Ethiopian coauthors sought and received research permissions from government authorities (including the Gedeo Zone Culture and Tourism Office, which in turn wrote permission letters to respective districts and lower administrative units). After receiving permission from government authorities, the Ethiopian coauthors sought and received permission from local elders and leaders of traditional institutions. Finally, the Ethiopian coauthors orally sought and received informed oral consent from each research participant. No minors were involved in this study. As ethical standards had been met by the Ethiopian coauthors, who collected all human subjects' data before the US-based author studies, environmental communication, and linguistic anthropology-specifically, context-rich framing, in-depth interviews, storytelling, and participatory mapping and observation. More than 30 participants took part in in-depth interviews and focused group discussions. We sought out heterogeneity in gender, education, age, livelihood, and religion in order to observe a range of environmental perceptions and communication. Because our methodology is purely qualitative, the level of data saturation determined the number of participants. We first did in-depth interviews with participants with whom three of the authors worked on previous projects. Using these contacts and the snowballing method, we added other participants from different districts. Those participants identified as youth are aged 18-34 years, a range considered youth according to local understandings. Those participants we identify as adults are aged 35-65 and have experienced at least two political regimes in Ethiopia. We use the term elders when identifying male study participants with status in traditional institutions or dispute resolution, and elderly when referring to male and female participants older than 65 . Both the elders and elderly might fall in the same age category but differ in terms of their status and role in the community.

In interacting with diverse participants, we focused on traditional beliefs, practices of environmental maintenance and regeneration, changes in livelihood practices, perceptions of relations with/in/as nature, and shifts in ecocultural meanings. We employed grounded theory (Emerson et al., 2010) and, more loosely, Cultural Discourse Analysis (CuDA) (Carbaugh, 2007) in analyzing the data, with the objectives of understanding core ecocultural premises and transformations in human-environment relations among the Gedeo. While grounded theory has been used to give leverage to researchers to thematically categorize data and generate concepts to link to broader theoretical frameworks, $\mathrm{CuDA}$ has been employed for its usefulness in analyzing the communication of culturally embedded discourses and meaning systems. Environmental researchers specifically have employed CuDA to identify largely unstated common sense ecocultural premises to make "explicit formerly taken-for-granted ecocultural knowledge and values" (Milstein et al., 2011, p. 493) in order to place them in "a domain of 'discursive scrutability"' (Carbaugh, 2007, p. 178).

This paper benefits from the involvement of a team of researchers from different disciplines-anthropology, geography and environmental studies, linguistics, and communication. Each team member contributed disciplinary theoretical and methodological insights to enrich the case study analysis within a multidisciplinary conversation. Moreover, while the three Ethiopian researchers position the paper within the Ethiopian context, substantiated in their lived experiences in the area, the American researcher interweaves broader theoretical arguments within environmental communication and ecocultural studies, bringing both interdisciplinary and international lenses to this Global South case study. Although none of the researchers is Gedeo, the three Ethiopian contributors are full time academic staff members of Dilla University in the Gedeo Zone, with long

joined the study, ethics approval was not needed from the US author's institution, or per US national laws and regulations. 
experiences of fieldwork among the Gedeo. Though we do not have insider understanding of the Gedeo experience and do not make such claims, being non-Gedeo provided an opening to learn about the issues we were studying, as participants considered us outsiders and, due to this, commonly went into detail in describing issues of interest. Moreover, the three Ethiopian contributors are Oromo and Konso-indigenous groups with strong traditional ecocultural values-and used both their academic and ecocultural foundations to help question and understand participants' meanings and experiences in this case study.

\section{Shifting Ecocultural Relations among the Gedeo}

Over recent decades, and particularly since the 1970s, the Gedeo have experienced significant shifts in their ecocultural relations both at the level of discourse and practice. Today, the confluence of three conflicting meanings within the ecocultural premise "tree is life" is evident among the people. These are: trees as ecologically and spiritually valued, trees as sources of monetary profit, and trees as instruments of conservation. Local people live within these tensions and tend to lean toward one of the three in perspective and practice. These competing perspectives point to ways contemporary Gedeo on-the-ground environmental practices emerge from tensions among wider economic, religious, conservationist, and traditional culturally embedded practices. Mirroring Ingold's (2000) argument that one's everyday encounter with his/her immediate surroundings influences how one understands that particular space, in Gedeo, one's environment is increasingly perceived from a short-term economic standpoint as the day-to-day experience of youth and adults with low incomes increasingly is dependent on cutting trees for cash to aid in profitbased survival. However, to understand the dynamics of the shift, it is imperative to situate it within the changes in the political economy at the national level.

Ethiopia as a nation has experienced changes affecting not only the country's overall political, economic, cultural, and environmental frameworks, but also those of multiple ethnic groups within its borders. This is due to the ongoing connectedness of top-down changes in national political discourses and ideologies to the rights (or lack of rights) of indigenous peoples to practice and exercise traditional cultural institutions, language, and religion. These top-down changes significantly challenged people's perceptions regarding ecological coexistence, and the Gedeo are no exception. Whereas the feudal regime (1890s-1974) first took away land from traditional communities to grant land, particularly in the conquered southern regions, to its feudal lords, the military regime (1974-1991) conversely nationalized all rural land in 1975 (Zewde, 2002). Under the current ethnic federalist regime (1991-today), which follows the developmental state as a system of political economy, land is in principle the property of all ethnic groups in their respective administrative units but, at the same time, remains under total government control.

Each change in land relations has been communicated and enforced through various channels by governmental actors. The national anthem of the Derg (military) regime, for example, contained verses that expressed, among other things, the virginity (in feminine gender) of the country's land: ...wenzoch terarochchish, dingil meretish...

...rivers your mountains, virgin your land

... '... your rivers and mountains, your virgin land, ...'

The use of "virgin" depicted the land as untouched, untapped, fertile, and potentially productive. The untouched connotation disregarded traditional embedded and reciprocal indigenous land practices. Likewise, the depiction connotes human beings, through state leadership, could/would take away the land's "virgin" state to convert it to human productivity needs and desires. The anthem and the following slogan, which was commonly used as a governmental motto in campaigns for development projects, reveal the military regime's dualist promotion of human separation from, and supremacy over, environment.

$\begin{array}{llll}\text { tefet'ron } & \text { k'ut'it't'ir } & \text { sir } & \text { innadergallen } \\ \text { nature } & \text { control } & \text { under } & \text { we will make }\end{array}$

'We will make nature under (our) control.'

The expression reflected and reproduced mastery environmental ontologies of the socialist military regime in that it promoted human dominance over, and subjugation of, the more than human world.

In current environmental discourses of Ethiopia's state government, notions of "green development" dominate state media and state authorities' public speeches. "Green development" centers scientific and "expert" knowledge as the ultimate truths in conservation approaches, emphasizing the role development "experts" play in changing human practices and actions on the environment, such as integrated watershed development, forest management (afforestation and reforestation), soil and water conservation, and water harvesting. At times, current government slogans echo the traditional Gedeo saying of "tree is life," appropriating this locally accepted ecocultural premise into conservation discourse. For example, we observed an expression written in Amharic - the working language of the federal government-on the Dilla town bus station and along roadside areas where the government operates conservation projects:

\section{zaf hiywet new Tenkebakebut! \\ tree life is you.take.care.of.it}

'Tree is life. Take care of it!'

The above expression, recently integrated into government conservation rhetoric in the Gedeo Zone, not only implies trees have core value to life, but also demands the reader's reciprocity marked by the imperative verb and the plural subject you on the verb. The statement situates the tree as an unequivocally important element that determines the existence of living things and the human receiver of the message as responsible for tree's nurturance. According to study participants, the above expression, reproduced today by the government, reflects traditional ecocultural foundational beliefs of Gedeo existence. In this regard, the government appropriates locally accepted wisdom and expressions as a culturally cohesive approach to channel down its conservation discourses. This appropriation is problematic as the government applies a dualistic approach and does not internalize 
the people's cultural values and practices of ecocultural knowledge. It is rather a systematic strategy of mobilizing the people within the government's agenda through the rhetoric of culturally accepted expressions. Whether it was the military regime's claim of mastery over nature or the current regime's conservation stewardship, these discourses are powerful instruments in shaping ecological perceptions and interactions.

We asked key Gedeo participants in the adult generation to tell us how they perceive and express ecocultural relations, specifically asking, "What is tree for you?" (in Gede'uffa: "Ha'no'a haqqichchi maachcho?"). Their common response was: "We cannot live without trees. Tree is life" ("Noo haqqe belo hedha dandena'non. Haqqichchi lubotten"). The expression elucidates traditional Gedeo understandings of trees as constitutive of their existence. Relatedly, elder Gedeo participants say they cannot exist detached from the land and, by giving the land what it needs, the land is encouraged to provide what humans need. According to an elderly woman in the Dilla Zuria district:

[O] ur land is part of our life. We cultivate it and get food from it. Through rituals we also provide the land what it needs. The land gets rain because of prayer, sacrifices, and thanksgiving rituals by our elders.

Gedeo elders attribute good coffee yields or lack of yields to harmonious or unharmonious human ecocultural behavior. According to these traditional views, the Gedeo get adequate rains, yields, and healthy coffee plants when elders perform regular rituals of thanksgiving and when traditional institutions function properly. For example, a 78-year-old elder stated that, in addition to religious and spiritual sanctions enacted by the Songo institution, rituals such as qeexala (asking Magano, ${ }^{11} \mathrm{a}$ monolithic God, to give rain or not hold back rain) performed by elders and elderly, are strategies still used to maintain harmony between humans and non-humans. Qeexala, a form of prayer and songs, is believed to enhance reciprocity between Magano and the Gedeo as people please the former and are reciprocated in the form of rain, peace, and fertility of their land and livestock. Such practices have for untold generations encouraged people to adhere to mutualist principles of indigenous institutions and refrain from transgressing traditional ethics, values, and rules.

In a different context, Klepeis et al. (2016) argue that the societies in northern Ethiopia protect church forests through hybrid models of protection, both as locally embedded spiritual and cultural values and as externally imposed practices for modern conservation purposes. For the Gedeo, trees also are used for spiritual purposes. For example, trees such as xibiro (Bersama abyssinica Fresen), laafaa (Brucea antidysenterica J. F. Mill), onoono (Trichilia emetica Vahl), deega (Celtis africana Burm. F.) Waleena (Erytherina abyssinica), adaamaa (Euphorbia abyssinica), and rejjee (Vernonia auriculifera) are vital components in performing rituals such as Qqeexala at Songo and Baalle. Elders carry the

\footnotetext{
${ }^{11}$ In Gedeo tradition, Magano represents a monolothic God without human features, unlike the Christian God. Magano is believed to exist high in the sky, but manifests through spirits that dwell in sacred spaces such as rivers, trees, and forests.
}

leaves of these trees during prayers or performing thanksgiving. In addition, the trees are given special places in interpersonal or public discussions. For instance, elderly participants described inflictions invoked upon a person who cuts laafaa, onoono, or deega for fuel or construction. Laafa is believed to make people weak when used for fuel whereas onoono and deega, respectively, are believed to bring conflict and poverty upon the users.

Furthermore, for the Gedeo, trees are part of social bonds in traditional contexts. An example is, when young people build new homes, they ask neighbors and close relatives to supply wood for roofs and walls. According to participants, a request to a relative or neighbor to acquire wood for construction materials cannot be rejected. The amount and quality of wood a person offers for construction of a new house show the degree of relationship between individuals, a practice mediating both human-human and human-tree relations.

According to elders of the Songo, a primary way traditional perceptions and practices are reinforced is through evening storytelling whereby elders narrate stories to children. In storytelling, traditional perceptions of "tree is life," and the associated mechanisms used to enhance respect for ecocultural ethics and discourage transgression of these ethics, are communicated from the older to the younger generation.

Another mode of communication to maintain mutualist harmony is in imposing strict sanctions and performing curses against individuals who transgress traditional values and ethics governing ecological interaction. In this context, the core ecocultural premise "tree is life" is also used as a communication practice to instill in the minds of the people values and meanings attached to trees. In the traditional context, people are informed about inflictions and misfortunes often through stories about those cursed as a result of harming the environment or invading sacred spaces. Sanctioning and casting out can also involve not participating in the burial of a deceased family member of a sanctioned person, not allowing him/her to take part in social activities, not herding cattle together, and so on.

Moreover, elder participants state that other ecological aspects, such as rivers and mountains, are essential elements of spiritual practices during conflict resolution enacted by the Songo and Baalle institutions. Different notions of the Earth in Gedeo tradition, such as life, mother, sacredness, and spirit, are used to communicate how people ought to interact, and the boundaries of interaction are reinforced through storytelling. A Gedeo elder stated:

The Earth is source of life for all living beings, like the mother nurtures the life of her babies. She is also sacred because she harbors spiritually and culturally important landscapes. She is home for spirits, good or bad. That is why we have to respect her.

While the gendered expression in the military regime's representation of the land as "virgin" characterizes it as an object to be subdued in the process of transforming it for utilization, the above expression by a Gedeo elder is embedded within the mutualist concept that represents the land as a mother who nurtures humans on the basis of respect and reciprocity. When asked to 
reflect on the current state of human-environment interactions, elder participants expressed strong feelings of frustration that traditional notions of mutualism, coexistence, and spiritual and institutional principles that reinforce coexistence are in jeopardy. They primarily point to the introduction of Western churches and schools, as well as introduced capitalism-oriented activities, such as logging and intensive construction that demands tree products and human labor, as changing patterns of ecological relations and weakening the indigenous institutions. Along these lines, a Gedeo elder fatalistically stated:

In the past, people respected our ritual spaces and the laws of the Songo. Young people obeyed elders and the culture. After the new religion [Protestant Christianity] came, they [members of the Christian faith, including missionaries, Gedeo, and other Ethiopians] denigrated our sacred spaces. The young people never listen to elders. They defend their ideas but do not listen to ours. Sometimes, they cut trees from cemeteries, Songo compounds, and other ritual sites. What can we do? The time is theirs.

Elderly participants further express how not only new religion but also monetization contributes to a lack of respect for traditional ontologies. One elderly participant stated:

Now people think in terms of money and Christianity. They do not give any respect to our ancestral norms and institutions such as the Songo.

Responses from focus group discussions with Christian participants provide a counter, and increasingly dominant, narrative. Christian participants state they are rejecting traditional Gedeo environmental practices because they now believe the Christian God vested ultimate authority upon human beings to control, utilize, and dominate all aspects of nature on Earth. They also say that the church considers traditional rituals and values attached to sacred spaces demonic, and, at the same time, their transgressions of traditional rules and practices are signs of strong spirituality and faith in Christianity. According to one of these participants:

Elders tell us that bad omen invokes infliction in the form of disease or whatever if we cut trees from graveyards and their ritual sites. They believe spirits inhabit those places. But we are free people now. God has set us free from evil spirits and bad omens. We don't care about what they believe in.

Unlike the mutualist Songo and Baalle institutions, churches enact a dualist ontology and lack environmental rules or sanctioning power over people who transgress ecocultural ethics of Gedeo society. From experiences in attending churches in these areas, we have never observed cases where church leaders connected changes in environmental conditions, such as drought and flooding, to human behavior. Rather, according to this perspective, only prayers to God are put forth as the routes of church engagement and only to intervene to solve purely social crises stemming from environmental degradation (Berkes, 2008; Tiedje, 2008). Similarly, although some northern Ethiopian communities consider church forests as sacred spaces, the sacredness emanates not from the people's representation of the environment as a conjointly constituted entity with humans. Rather, by enclosing the church and its buildings, which are perceived as sacred, the forests get values of sacredness, and as a result, people are sanctioned not to cut trees from such spaces (Klepeis et al., 2016).

Participant statements illuminate not only the elders' and elderly's sense of helplessness in the face of a generation turning its back on traditional ontology, but also another related shift in Gedeo core ecocultural premises-that of time. The elders point to a current marked chronological shift toward a dualist ontology of the youth. For example, an elder participant states that "the time is theirs [time belongs to the youth]" while the Christian participants emphasize, "now" as "free people," they are no longer tied to spirits and omens that "inhabit" places. Tied up in this current shift from mutualism to dualism is a shift from traditional perceptions of time, understood in forms of reciprocity among individuals and entities, to time as having monetary value. This shift is felt in praxis in examples of youth leaving subsistence (unpaid) farming work to take up wage-based work in town and in community members, formerly expected to provide help freely upon request, starting to ask for money for time they work for a neighbor or relative.

The commodification of time mirrors, and relates to, the shift to a dualist ontology, to a commoditized environment, and to the massive increase in cutting and selling of commoditized fuel wood and timber, as well as a rising inclination toward the production of cash crops such as the stimulant shrub khat (Catha edulis), eucalyptus trees, banana plants, and fruit-bearing trees, such as avocados and mangos. Some of these plants (e.g., khat) and trees (e.g., eucalyptus) are exotic to the land and, as they are planted for economic value, are increasingly replacing indigenous trees and, thereby, disrupting local ecosystems. A young Gedeo man summarizes his views on the generational shift to commodification as follows:

In the past, our forefathers were conservative and unable to use the resources at their disposal. Why do people become hungry while there is money [trees to sell] in their garden? What is the use of that big tree if it does not rescue me from my financial crisis? Now, people are civilized. Our generation is not like that of our fathers' or forefathers' time. We care for the trees because they are money. Those people in the past were looking after the trees but they did not use them. My village mates make big money out of selling wood for house consumption (i.e., firewood) and construction materials just from the forest or even gardens. Look at this nice tree. It is money. It is money in pocket but the owner does not know that.

The participant considers the practice of cutting down trees for commercial purposes as a chronological indicator of civilization, viewing monetization as equivalent to advancement or Western notions of progress. His dualist ontology disregards subsistence 
and ecologically regenerative use as valid use. The notion of "tree is life" is transformed into tree "is money."

An increasing demand for firewood and timber, especially in towns, has necessitated a constant supply of wood. A 25-year-old Gedeo youth, whom we found cutting birbirra (Melltia Furgunnia) from his parents' garden for firewood, states:

For the last 7 years, my life has been dependent on selling firewood. You know what? For me, these trees you see in this coffee field are much more important than any other resources. For my family and me, birbirra is just money in pocket. You just cut it down today and it is cash tomorrow. There is no worry to get it dry. It burns even immediately after it is chopped into pieces. Other trees don't have market value as birbirra as such but we combine them with this important tree. In the past, people used to talk about its use for coffee as a shade. But how can a person think of tomorrow while today is uncertain. We need to eat today in order to live tomorrow.

The inclination toward commodification (e.g., tree "is just money in pocket") among young people emanates not only from commoditization of environment and a related short-term orientation to time, and from the ongoing destruction of a subsistencebased traditional ecoculture and resultant precariousness and vulnerability, but also from poor money-saving practices in the context of emergent consumer capitalism in the zone. For example, the Gedeo produce the internationally trademarked Yirgachefe organic coffee that yields a substantial amount of income during coffee season for the majority of people in the zone. This income, however, does not stay long and the local people are influenced by consumerist behavior, spending money on luxury materials such as jewelry, alcohol, expensive radios, high cost clothes and shoes, expensive mobile phones, etc. For example, a study participant complained about the behavior of the youth as follows:

Our children are infected by bad habits such as alcoholism, and spend almost all of their income on expensive items. In few months time, they run out of money and begin selling basic house utensils.

Although some of these expensive items, such as radios and mobile phones, contribute to acquainting the local people with information beyond their localities, none generates household income. Study participants indicated that most of the people face financial shortages during non-coffee seasons and turn to cutting and selling indigenous trees partly due to financial mismanagement as well as absence of other means of earning income.

The Gedeo Zone's political ecological contexts have been transformed through a succession of new regimes and the influx of Protestant churches, as well as global neoliberal capitalist structures in which the Gedeo economy is integrated into the global market through the coffee trade. As such, we are witnessing a seemingly inevitable shift from a stable traditional ecoculture built upon institutions that provided both ecological and social support and sanctions to a less stable existence built upon individualism and extractive practices. This shift includes an emphasis on short-term dualist planning and an eschewing of long-term mutualist thinking. The new dualist ontology has loosened social cohesion maintained through indigenous institutions and disrupted the ecosystem regenerated through traditional agroforestry. More specifically, whereas the decline of Baalle and Songo institutions reduces the sanctioning power of these institutions, the dwindling practice of the baboo tradition reduces the regeneration of the ecosystem and the sustainability of the agroforestry.

Based on our field observations, state agricultural supervisors and DAs respond to this decline by advocating global scientific notions of conservation. Instead of traditional spiritually mandated environmental relations, state discourse focuses on conservation actions in the form of broader utilitarian and economic perspectives through, for example, enhancing land productivity by constructing physical structures (like terracing, bunds, and cutoff drains). Most of the conservation measures practiced in the area are not part of the experiences and knowledge of the local people, yet both scientific and traditional notions are produced within certain forms of ecological knowledge and communicated accordingly.

While we delve deeper into the scientific notions of the state below, we can begin here to delineate interpretations of three different ontologies embedded in the same linguistic expression "tree is life" commonly used by Gedeo elders, government DAs, and Gedeo youth. For Gedeo elders in the traditional context in which their culture, beliefs, and values are strongly intertwined with a mutual coexistence with the land, the expression connotes a spiritual and interrelated subsistence and thriving of humans and trees. Unlike elders, who still maintain the skills and knowledge of long-term planning for generations of offspring in their ecological relations, the younger generation appears to have lost both this commitment and insight and conversely consider trees as commodities providing short-term gain. As we illustrate further below, government authorities and agents use the expression "tree is life" mainly from conservation orientations, building on the global movement for climate disruption mitigation and adaptation through reforestation.

While both indigenous practices and views of the modern state focus on approaches that are restorative, views from the youth incline toward an extractivist utilitarian paradigm with no long-term focus or subsequent concern for sustainability. In this regard, we see manifested scholarly assertions (Pàlsson, 1996; Merchant, 2003) that cultures enter processes of change from mutualist, reciprocal, and ecocentric to dualistic, extractivist, and anthropocentric within the context of ever-expanding and globalizing consumer capitalist understandings of environmental relations.

\section{Environmental Communication and the Creation of Environmental Subjects}

Human-environment interactions produce, and are produced by, environmental communication and at the same time yield environmental subjects. Environmental subjects are created when actors and institutions inscribe a certain value or rule upon 
human-environment interactions through coercion, cooptation, remuneration, or education (Agrawal, 2005; Fletcher, 2010). Fletcher (2010) adds there are two crucial strategies dominant actors use in creating environmental subjects: punishment and discipline.

In the Gedeo case, environmental subjects have been created both in the traditional and modern contexts. In the past, respecting the orders of Songo elders, fear of punishment, social exclusion, and expectations of environmental affordance (i.e., reciprocity) constituted the processes of creating environmental subjects. A Gedeo elderly woman in her 70s stated:

In the past, when we were girls, we were not allowed to collect firewood from sacred areas. Cutting trees, even collecting dry wood for firewood from graveyards, Songo compounds, and other sacred places where rituals were performed was feared for invoking inflictions. Songo elders also punished people who cut trees from restricted areas. The punishment was not in terms of money. Rather, they isolated you from the community so that you could not take part in social activities if the Songo passed a verdict of exclusion upon you. That was why we collected firewood and men also cut trees from areas not prohibited.

Whereas the sanctions of Songo and Baalle institutions contributed to social and ecological harmony in the past, their decline has led to fragmentation. Today, it is largely only the elderly who adhere to traditional beliefs and refrain from using traditionally protected indigenous trees because they believe they would face social sanctions as well as bad omens. The following statement from another elderly Gedeo woman illustrates generational difference:

We were told from the childhood period that cutting degaa and onoono, and there are also other types of trees I forgot them now, resulted in changing good luck to bad. For example, if you met a person on your way carrying these trees, you definitely would feel that you would face something bad. But, nowadays, the young people are not worried about whatever infliction a bad omen would create.

Gedeo elders continue to believe the environment can restrict its bounty in response to extractive or disrespectful behavior and, conversely, reciprocate for their harmonious coexistence. Chen (1993) argues many indigenous peoples around the world interact with their immediate surroundings in anticipation of environmental affordances based on their environmental behavior. Other scholars argue the majority of indigenous peoples developed a mutuality-focused ecological wisdom that enabled them to live sustainably for thousands of years (Berkes, 2008; Descola, 2013).

In this regard, there is a strong belief among the majority of the Gedeo that the recent variability in climate, decline in land productivity, and crop failure are consequences of people's mismanagement of their environmental relations. Interestingly, this perspective transcends social categories such as age, education, and gender, though ecological knowledge varies according to exposure to different communication channels. For example, while both rural youth and Gedeo conservationists subscribe to this notion, they may differ from Gedeo elders in terms of solutions. Whereas younger Gedeo and conservationists focus on changing human actions of environmental degradation through education and punishment, elders suggest reconciliation between humans and Magano as the latter may have invoked infliction upon people for their ecological mistreatments.

In explaining reconciliation, elders speak about practices of reciprocity and respect in terms of protecting the land from destructive activities, maintaining harmony, and offering rituals and prayers. One elder participant, who served both as a member of the local government conservation program and as Hayyichcha (a member of the Songo council), weaves together both traditional and conservationist premises of "tree is life" in his solution:

Nature does not give its blessings to people when people do not behave ethically. The traditional skills of slashing and pruning and all care people used to give to trees are now vanishing. How would we expect good yield from coffee and ensete when there is no employment of the time-tested indigenous knowledge? It is impossible to think of good coffee and ensete yields unless our people not only revert to maintaining our cultural values but also add what the government has brought for us through these development agents.

Elders still communicate traditional environmental values to children through stories that narrate, for example, how a monster ate a person upon entering a forest, graveyard, or sacred space to cut a tree. Through such storytelling methods and ritual performances such as Qeexala, the elders and traditional institutions continue to attempt to manage public conduct by labeling a person as "bad" or "good" depending on environmental behavior. The association between social values and corresponding environmental interactions creates a type of environmentality (Agrawal, 2005), creating environmental subjects by inculcating values pertaining to mutualist coexistence. The Gedeo, until very recently, have maintained their ecosystem intact and built a strong traditional environmentality. In the past, because of the sanctioning power of the traditional institutions and the institutionally enforced core "tree is life" premise of mutualist coexistence, the notion as well as the practice of commodification of trees was rarely possible.

However, this study is interested in the discursive transformations underway in the face of shifts in balances of power. The introduction of capitalist commerce, Western world religion, and education systems, on the one hand, and rapid urbanization, population growth, and prevailing ecological problems such as climate disruption, pests, and disease, on the other hand, together challenge the power of elders and indigenous institutions. According to our elder participants, what frustrates them most is increasingly young people are joining the Christian religious sects such as Mekane Yesus, Kale Hiwot, Mulu Wengel, etc., which in turn weakens the traditional belief systems and institutions and makes mutualist human-environment interaction a quickly 
receding ontological practice of the past. A member of Baalle council stated:

The new religion is now taking away young people. This Protestant religion has made young people disobedient to our culture. They don't listen to what elders say. They are not afraid of transgressing traditional rules. For example, they dare to cut trees from graveyards. I am worried that their behavior might invoke infliction upon our society.

In addition to new dualist religious ontologies, elders point to institutionalized education as having a strong impact on environmental interaction. The central government introduced institutionalized education in the 1960s to replace traditional education passed from generation to generation through oral knowledge. Since that time, successive governmental regimes have worked to replace traditional education or knowledge transfer systems by formal government education as a sign of "modernization." The government education does not incorporate local traditional norms, values, and knowledge, and, thus, detaches school children from their community's ways of thinking and knowledge transfer. Institutionalized state education, in part, is responsible for schooled people looking down on traditional institutions and ecological norms of agroforestry, considering both backward. The phenomenon of introducing Christianity and modern education, in concert with the influx of consumer capitalism, instills dualist notions of utilitarianism and human dominion over nature in today's emerging environmental subjects among younger Gedeo.

Government conservation policy employs different strategies to create environmental subjects, which include strict forms of community surveillance and criminal punishment for individuals who transgress state environmental laws and rules. To govern conduct, the government has established a new structure in every institution down to the village/neighborhood level, in which people are organized into "developmental armies" comprising six individuals who work together, with each member monitoring the other. One of the six individuals is assigned as team leader and " 1 to 5 team" members meet weekly or every 2 weeks to discuss any social and environmental issues in their community. This local arrangement is ecoculturally quite different from the traditional Songo because, unlike the Songo institution, which situates environmental interactions within Gedeo cultural and spiritual contexts, the government arrangement situates these interactions within expert-based conservation knowledge and surveillance. A team leader of one such group stated:

Every member of the society is under surveillance through 1 to 5 arrangements. People who cut endangered indigenous trees such as cordia African and use them for timber production are now easily identified and brought to justice. In order to avoid punishment in terms of fines or imprisonment, people respect the rules.

Whereas both traditional and state approaches use punishments to discipline behavior, and these practices worked within traditional institutions' networked and spiritually based ecocultural mutualist system, the developmental armies do not have the same efficacy in adequately stopping people from illegally cutting the most endangered indigenous trees, such as cordia African and podocarpus. Transgressors use eluding techniques such as sneaking into the forest at night. Our field observations also found that trees, cut in such a way, are secretly sold in nearby towns at reduced prices. While ineffective as an approach, the participant's view illustrates how the state's strategy of creating environmental subjects has become inculcated into the culture. Traditional Gedeo approaches of creating environmental subjects were through social and spiritual sanctions, but the government's far less effective strategies are through legal sanctions.

Just as traditional and government approaches share similarities in exercising punishment as a strategy, notions of reciprocity are also used in both contexts to shape perceptions and actions about environmental relations. Again, however, praxis differs. In the state approach, government authorities try to reward local communities for positive environmental behaviors through a "safety-net"12 program. While traditional ecocultural notions of reciprocity dwell in the understanding that nature reciprocates people for positive environmental behavior, in the case of the more dualist ontology of the state, it is the government that reciprocates. Similarly, the government uses notions of ecosystem services in educating local communities about what the more than human world provides, and the government accesses cultural, economic, ecological, and spiritual environmental values as a strategy to fit into the local communities' traditional ecocultural norms so that conservation discourses can be easily internalized. The government is cognizant of challenges it would face from local communities if it tried to impose purely top-down approaches, thus it appropriates locally accepted values and practices and adopts them to its own conservation programs as it tries to mobilize people for implementation of its conservation programs. It is imperative to reiterate that both Gedeo traditional approaches and state conservation approaches are meant to shape sustainable environmental perceptions and behaviors of the community. However, while Gedeo traditional notions of mutual coexistence are/were embodied in their locally constituted ecocultural beliefs, norms, and institutions, the government's subscription to the expression of "tree is life" is instituted within broader global environmental discourses and legal structures.

\section{DISCUSSION}

Over the past 100 years, but at an increasingly rapid pace during recent years, the Gedeo people have encountered various outsider forms of introduced competing narratives that have continued to challenge and weaken their traditional ontology of mutualism. Changes in national political dynamics have significantly weakened the legitimacy of traditional institutions and reciprocal environmental interactions at local levels. Competing narratives include state paradigms that first centered mastery and control

\footnotetext{
${ }^{12}$ The program is a new approach of attaching aid incentive to some development projects. In the Gedeo case, for example, a village that demonstrated high performance in conservation would be given access to the safety-net program (e.g., food aid, loans).
} 
and, now, reward and punishment to encourage environmentality. In addition, Gedeo and Ethiopia as a whole have encountered paradigms of the market economy and urbanization that center commodification, as well as paradigms of Western Christianity and institutionalized state education that devalue traditional ecological knowledge and center the human. Today's Gedeo youth appear to largely dismiss traditional cultural and spiritual values of agroforestry of the elders and the countless generations that preceded them. We argue competing forms of ecological knowledge are evident within both institutional and intergenerational dimensions.

At the scale of institutions, practices, rules, and ontological narratives of environment in the traditional context appear similar to, but also fundamentally differ from representations, policies, and approaches advocated via contemporary state conservation institutions. Intergenerationally, elders' mutualist ontology greatly contrasts with dualist ontologies of the youth. In this case study, we illustrate an ongoing change in the Gedeo core ecocultural premise of "tree is life" from the spiritual ontology of trees as reciprocators in sustaining the very existence of ecologically related beings and processes to the economic ontology of trees as commodities in securing individual monetary livelihood for the short-term. The narrative of "tree is life" in government discourse brings in another competing ontology of trees as mitigating climate disruption, diffusing global discourses of environmental conservation, reforestation, green development, and climate disruption mitigation at the local level. As such, in "tree is life," different premises circulate in dynamic tension.

These related but conflicting meanings of "tree is life" illustrate ways new forms of environmental knowledge, discourse, and practice emerge both in competition and cooperation with people's indigenous environmental ontologies. In this context, emerging environmental narratives are informed by competing notions as well as interests of various actors. In the past, the power of elders and traditional institutions prevailed in the maintenance, monitoring, and narration of ecocultural interaction. However, this study details how the involvement of various actors, such as the developmental state, externally imposed religion, state institutionalized education, and globalizing neoliberal market forces has changed the power balance. Moreover, the appearance of international conservation institutions on the scene, including UNESCO, has contributed to a shift toward "expert" knowledge in environmental conservation, adding a partially traditionally reflective narrative. Within these conflicting and coinciding discourses, two competing dualist forces-the government's conservationist paradigm and the young generation's short-term profit paradigm-emerge as predominant while elders' notions of mutualism are vanishing.

Although the government conservation attempts are geared toward maintaining and restoring weakened indigenous practices, at their core they promulgate a strongly competing ontology. Whereas Gedeo traditional ontology places humans and nonhumans in mutually subsisting and reciprocal relations, the state conservation paradigm is paternalistic, positioning humans with absolute power to shape and influence the form and structure of the environment. The related weakening of the Songo and Baalle institutions giving way to the strengthening of institutions such as churches introduced through state administration (in the case of the Orthodox church) and missionaries (in the case of Protestant churches) in all corners of the Gedeo Zone (McClellan, 1988) have provided further ontological framing for young people turning their backs on traditional Gedeo belief system and institutions.

More broadly the findings of this interdisciplinary study can serve as empirically supported interpretations that can be applied to the study of other in-process ecocultural ontological and material changes within different contexts. Intergenerational and institutional shifts in ecocultural interests and perspectives threaten the continuity, sustainability, and regenerativity of agroforestry systems in the Gedeo Zone, and similar shifts are at play in different settings around the world. For example, the different representations of spaces as sacred, home, and ritual by indigenous communities in the US and India, and conversely the designation of the same spaces as nuclear waste zone and tourist centers by federal governments (Endres, 2012; Ormsby, 2013) similarly illustrate ways human regenerative or destructive practices are shaped by ontological orientations (Ingold, 2000). Attending to these overwhelmingly uni-directional global shifts from mutualism to dualism is imperative to all crisis focused disciplines as our very continued existence as a species interwoven with others of this planet depends on retaining and regenerating restorative ways of being, relating, and dwelling. As dualistic ontologies continue to prevail, the ecocultural agency and sanctioning power of traditional institutions and mutualist systems are increasingly gravely endangered and increasingly need to be heard.

\section{ETHICS STATEMENT}

The study presented in the manuscript involved human subjects, and thus we followed ethical procedures accordingly. The research was conducted according to Dilla University Research Policy but there is no ethics committee in the university. Upon meeting the ethical standards of the University's Research Policy, we sought and got research permissions from different government authorities (e.g., Gedeo Zone culture and tourism office that in turn wrote permission letters to respective districts and lower administrative units). After we cleared permission from government authorities, we also sought and got permission from local elders and leaders of traditional institutions. Finally, we received informed consent from research participants. The US-based coauthor joined the project after data collection and initial analysis had been completed. The Ethiopian coauthors can provide a signed letter from their institution if requested.

\section{AUTHOR CONTRIBUTIONS}

All authors equally contributed to this paper and, thus, share equal authorship. 


\section{REFERENCES}

Agrawal, A. (2005). Environmentality: Technologies of Government and the Making of Subjects. Durham: Duke University Press.

Berkes, F. (2008). Sacred Ecology. London: Routledge.

Brulle, R. J. (2010). From environmental campaigns to advancing the public dialog: environmental communication for civic engagement. Environ. Commun. 4, 82-98. doi:10.1080/17524030903522397

Cantrill, J., and Oravec, C. L. (1996). The Symbolic Earth: Discourse and Our Creation of Environment. Lexington, KY: University Press of Kentucky.

Carbaugh, D. (1996). Situating Selves: The Communication of Social Identities in American Scenes. Albany, NY: State University of New York Press.

Carbaugh, D. (2007). Cultural discourse analysis: communication practices and intercultural encounters. J. Intercult. Commun. Res. 36, 167-182. doi:10.1080/17475750701737090

Chen, K. (1993). Environmental affordance: a theoretical framework for incorporating some behavioural considerations in residential evaluation. Forum 2, 57-64.

Clarke, T. (2017). The construction of Goshute political identity: negotiation of voice regarding nuclear waste policy development. Front. Commun. Sci. Environ. Commun. 2:7. doi:10.3389/fcomm.2017.00002

Cox, R., and Pezzullo, P. (2015). Environmental Communication and the Public Sphere, 4th Edn. London: SAGE.

Couldry, N. (2010). Why Voice Matters-Culture and Politics after Neoliberalism. Thousand Oaks, CA: Sage Publications.

CSA. (2007). Population and Housing Census of Ethiopia. Addis Ababa: Central Statistical Agency.

Descola, P. (2013). Beyond Nature and Culture. Chicago: The University of Chicago Press.

Descola, P., and Pàlsson, G. (eds) (1996). "Introduction," in State and Society: An Anthropological Perspective (London: Routledge), 1-22.

Emerson, R., Fretz, R. I., and Shaw, L. L. (2010). Writing Ethnographic Notes. Chicago: Chicago University Press.

Endres, D. (2012). Sacred land or national sacrifice zone: the role of values in the Yucca Mountain participation process. Environ. Commun. 6, 328-345. doi:10.1080/17524032.2012.688060

Fletcher, R. (2010). Neoliberal environmentality: towards a poststructuralist political ecology of the conservation debate. Conserv. Soc. 8, 171-181. doi:10.4103/0972-4923.73806

Hudson, G. (1981). The highland east Cushitic family. Vine Spracheunde Geschichite Afrika 3, 97-124.

Ingold, T. (2000). The Perception of the Environment. London: Routledge.

Kippie, T. (2002). Five Thousand Years of Sustainability? A Case Study of Gedeo Land Use (Southern Ethiopia). Netherlands: Treemail Publishers.

Klepeis, P., Orlowska, I., Kent, E. F., Cardelús, C. L., Scull, P., Eshete, A. W., et al. (2016). Ethiopian church forests: a hybrid model of protection. J. Hum. Ecol. 46, 715-730. doi:10.1007/s10745-016-9868-z

Legesse, A. (2014). The Dynamics of Gedeo Agroforestry and Its Implications to Sustainability. PhD Dissertation, UNISA, South Africa.
McClellan, C. (1988). State Transformation and National Integration: Gedeo and the Ethiopian Empire, 1895-1935. East Lansing: Michigan State University.

Merchant, C. (2003). Reinventing Eden: The Fate of Nature in Western Culture. London: Routledge.

Milstein, T. (2009). "Environmental communication theories”, in Encyclopedia of Environmental Theory, ed. S. L. Foss (Thousand Oaks, CA: SAGE), 344-349.

Milstein, T. (2011). Nature identification: the power of pointing and naming. Environ. Commun. 5, 3-24. doi:10.1080/17524032.2010.535836

Milstein, T., Anguiano, C., Sandoval, J., Chen, Y. W., and Dickinson, E. (2011). Communicating a "new" environmental vernacular: a sense of relationsin-place. Commun. Monogr. 78, 486-510. doi:10.1080/03637751.2011. 618139

Orderud, G., and Vogt, R. (2016). Environmental values and attitudes among farmers in China - a case study in the watershed of Yuqiao reservoir of Tianjin Municipality, China. Int. J. Environ. Stud. 73, 917-938. doi:10.1080/00207233. 2016.1220699

Ormsby, A. (2013). Analysis of local attitudes toward the sacred groves of Meghalaya and Karnataka, India. Conserv. Soc. 11, 187-197. doi:10.4103/0972-4923.115722

Pàlsson, G. (1996). "Human-environmental relations: Orientalism, paternalism and communalism," in State and Society: An Anthropological Perspective, ed. P. D. Pálsson (London: Routledge), 63-81.

Plec, E. (Ed.) (2013). Perspectives on Human-Animal Communication: Internatural Communication. London: Routledge.

Robbins, P. (2012). Political Ecology: A Critical Introduction, 2nd Edn. West Sussex: Wiley-Blackwell.

Schuetze, C. (2015). Narrative fortresses: crisis narratives and conflict in the conservation of Mount Gorongosa, Mozambique. Conserv. Soc. 13, 141-153. doi:10.4103/0972-4923.164193

Tiedje, K. (2008). Situating the corn-child: articulating animism and conservation from a Nahua perspective. J. Stud. Relig. Nat. Cult. 2, 93-115. doi:10.1558/ jsrnc.v2i1.93

Turton, D. (2011). Wilderness, wasteland or home? Three ways of imagining the Lower Omo Valley. J. East. Afr. Stud. 5, 158-176. doi:10.1080/17531055.2011. 544546

Zewde, B. (2002). A History of Modern Ethiopia, 1855-1991. Addis Ababa: Addis Ababa University Press.

Conflict of Interest Statement: The authors declare that the research was conducted in the absence of any commercial or financial relationships that could be construed as a potential conflict of interest.

Copyright (c) 2017 Regassa Debelo, Legesse, Milstein and Orkaydo. This is an open-access article distributed under the terms of the Creative Commons Attribution License (CC BY). The use, distribution or reproduction in other forums is permitted, provided the original author(s) or licensor are credited and that the original publication in this journal is cited, in accordance with accepted academic practice. No use, distribution or reproduction is permitted which does not comply with these terms. 